\title{
Das ações, das intenções e das mãos: formação do grupo de artesanato da Casa dos Girassóis ${ }^{*}$
}

\author{
Erica Ribeiro de Andrade \\ Eugenio Andrés Díaz Merino ${ }^{2}$ \\ Universidade Federal de Santa Catarina
}

Este artigo ${ }^{3}$ apresenta os resultados parciais do trabalho de campo realizado em abril de 2011, na cidade de Florianópolis, Santa Catarina, como parte da coleta de dados para pesquisa de mestrado em Gestão de Design. O objetivo deste trabalho de campo foi conhecer as motivações pessoais das integrantes do grupo de artesanato em formação na entidade filantrópica Casa dos Girassóis em participar deste grupo com foco na produção e comercialização, buscando-se evidenciar suas intencionalidades. Utilizou-se como base teórica o conceito de agência apresentado por Ortner (2007) e as leituras sobre trabalho de campo e o papel do pesquisador em campo, com Wacquant (1996) e Foote-Whyte (1980). Como resultados parciais, este trabalho de campo possibilitou uma imersão no grupo, permitindo conhecer pessoalmente cada agente e elucidar questões referentes ao impacto que motivações pessoais poderiam causar no objetivo principal do grupo: gerar renda para ajudar a entidade a manter seus trabalhos na comunidade.

Palavras-chave: Trabalho de Campo-Artesanato - Design - Pesquisa Etnográfica
This article presents partial results of fieldwork conducted in Florianópolis city (Santa Catarina, Brazil), April 2011, as part of data collection for research master's degree in Design Management. The objective of this study was to understand the personal motivations of members of the group of crafts of the Casa dos Girassóis to join this group focused on the production and marketing, aiming to reveal its intentions. Was used as a theoretical basis the concept of agency presented by Ortner (2007) and the readings on field work and the role of researcher in the field with Wacquant (1996) and Foote-Whyte (1980). As partial results, this fieldwork enabled an immersion in the group, allowing to know each agent personally and clarify issues regarding the impact that personal motives could cause the main purpose of the group: generate income to help the organization to keep it work in the community.

Keywords: Fieldwork - Craftword - Desing - Ethnographic research

\footnotetext{
*About actions, intentions and hands: organization of the group of crafts of the House of Sunflowers ${ }^{1}$ Endereço para correspondências: Erica Ribeiro de Andrade, Praça Julio Mesquita, 68, Apto. 161, Santa Efigênia, São Paulo, SP, 09012-010 (Telefone: 0115117 3922)

${ }^{2}$ Eugenio Andrés Díaz Merino, Núcleo de Gestão de Design, Centro de Comunicação e Expressão, Bloco A, Sala 113, UFSC, Campus Universitário, Florianópolis, SC, 88040-970 (Telefone: 048 37216403 )

${ }^{3}$ Artigo elaborado para disciplina Antropologia Cultural, do Programa de Pós-graduação em Antropologia Social da Universidade Federal de Santa Catarina, ministrada por Miriam Grossi e Carmen Rial no primeiro semestre de 2011.
} 


\section{UMANAS}

\section{Apresentação}

trabalho de campo aqui apresentado constituiu uma das etapas da pesquisa de mestrado realizada entre março de 2010 e março de 2012, na cidade de Florianópolis, Santa Catarina. Integrante de uma pós-graduação em Design, o diálogo com a antropologia ocorreu pela percepção de lacunas na pesquisa, em relação a metodologias do trabalho de campo e de questões teóricas relacionadas ao tema da pesquisa. A pesquisa constituiu-se em um Estudo de Caso do grupo de artesanato da entidade filantrópica Casa dos Girassóis e teve como objetivo geral "Investigar de que forma o design interfere nos aspectos da dimensão econômica da sustentabilidade nos Grupos Produtivos de Pequeno Porte produtores de artesanato".

O diálogo teórico estabelecido entre a pesquisa em design e os estudos em antropologia foram focados no trabalho de campo, com os autores Loïc Wacquant (1996) e William Foote-Whyte (1980), no conceito de agência com a autora Sherry Ortner (2007) e nas ferramentas do design participativo com o autor Carlo Vezzoli (2010). O trabalho de campo se caracterizou como uma pesquisa participante utilizando-se da observação direta, de entrevistas semi-estruturadas individuais, com registro filmográfico e fotográfico, além de anotação direta. Todas as pessoas entrevistadas concordaram em participar das entrevistas e foram previamente esclarecidas sobre os objetivos da pesquisa e suas formas de publicação. Primeiramente será apresentada fundamentação teórica, evidenciando o diálogo estabelecido entre o campo e a teoria estudada. Posteriormente, será apresentado o grupo do estudo de caso e os objetivos do trabalho de campo. Em seguida, serão colocados os resultados do campo e as considerações desta autora. Este texto apresenta resultados parciais, dúvidas e descobertas do campo aqui apresentado.

\section{Trabalho de campo e agência: contribuições para uma pesquisa em design}

Nesta seção, serão apresentados brevemente dois temas que contribuíram para a construção do trabalho de campo aqui apresentado e a sua reflexão, sendo eles, o trabalho de campo e o conceito de agência. Dois pontos referentes ao trabalho de campo contribuíram para sua construção: o campo e o papel do pesquisador. Com Roberto Da Matta (1981), tem-se um entendimento do trabalho de campo por meio da metáfora do "rito de passagem". Toda imersão que o pesquisador precisa realizar: seu afastamento de sua realidade, o mergulho na realidade do observado e o retorno para a sua realidade (renovado, modificado), são as etapas básicas do rito de passagem: "morte", "liminaridade" e "ressurreição". Nesta pesquisa, chegou-se à reflexão se esta imersão é 


\section{Das ações, das intenções e das mãos: formação do grupo de artesanato da Casa dos Girassóis}

possível de ser alcançada em períodos curtos, caso da pesquisa de mestrado, por exemplo, que não excede dois anos e que tem o trabalho de campo reduzido, na melhor das hipóteses, a 4 meses. Seria possível adentrar no grupo pesquisado, conhecer sua organização interna e as motivações individuais de suas integrantes em tão pouco tempo?

Por sua vez, sobre o papel do pesquisador em campo William Foote-Whyte (1980) apresenta em seu texto Treinando a observação participante pontos importantes sobre o papel do antropólogo no campo, seu comportamento e interferências nas informações coletadas. Questões como: O que acontece quando o pesquisador não está por perto, Qual é o momento para perambular sozinho (sem seu informante) no local de campo? Como explicar sua presença no local? O quanto se envolver nas questões cotidianas do grupo? orientaram esta pesquisa, principalmente por se tratar de um campo familiar e aberto, no qual o envolvimento pessoal com as pessoas pesquisadas e a própria entidade seria difícil de controlar.

Neste sentido, o conceito de agência vem embasar a reflexão sobre o campo, especialmente no entendimento das motivações pessoais das pessoas pesquisadas, inclusive desta pesquisadora, e das relações sociais que permeiam o grupo. Para este conceito, utilizou-se Sherry Ortner (2007). A autora apresenta primeiramente o conceito de jogos sérios como "formações culturais, não modelos de analistas"... (que) "pressupõe atores culturalmente variáveis (e não universais) e subjetivamente complexos (e não predominantemente racionalistas e interessados em si mesmos)" (ORTNER, 2007; p. 46), considerando que, os "jogos sérios" pressupõem que "todos os atores sociais 'têm' agência". O conceito de agência pode ser entendido a partir de seus elementos constitutivos: 1) "A questão da intencionalidade" que se apresenta como a base do que significa agência, em sua ampla gama de estados (cognitivos, emocionais, em vários níveis de consciência), e podendo incluir "enredos, planos e esquemas altamente conscientes; metas, objetivos e ideais um pouco mais nebulosos; e finalmente, desejos, vontades e necessidades que podem variar de profundamente encobertos a bastante conscientes." (ORTNER, 2007, p. 52); 2) "A questão da construção cultural da agência" que, semelhante à linguagem, mesmo sendo uma capacidade humana ter agência, ela se configura de formas diferentes nos variados tempos e lugares (ORTNER, 2007; p. 55); e 3) "Relação entre Agência e Poder" na qual a autora compreende que "a capacidade de transformação dos agentes é apenas uma dimensão de como o poder opera nos sistemas sociais" (ORTNER, 2007, p. 56). Um alerta que Ortner faz, reportando-se aos Comaroff, diz respeito à indissociabilidade da intencionalidade dos atores das forças sociais e culturais que os permeiam. Diz a autora: 


\section{HUMANAS}

Se uma análise que focaliza excessivamente as intencionalidades dos atores perder de vista as forças sociais e culturais de grande escala que estão em jogo, também perderá de vista - temem os Comaroff - as relações complexas, e altamente imprevisíveis, entre intenções e resultados (ORTNER, 2007; p. 49).

Estes dois temas constituem a base deste trabalho de campo e surgem no decorrer do texto entremeando as informações apresentadas e os relatos desta pesquisadora, bem como suas reflexões e inquietações com o campo.

\section{A Casa dos Girassóis: artesanato como meio de autoconhecimento e geração de renda}

O estudo de campo ocorreu na sede da Casa dos Girassóis, entidade formada a partir da iniciativa de um grupo de colaboradores voluntários da Associação Espírita Fé e Caridade, em possibilitar aos moradores da comunidade Mont Serrat (vizinha à entidade), formação humana integral a partir das bases da doutrina espírita. A entidade se localiza na Rua Monsenhor Topp, 320, Centro de Florianópolis, Santa Catarina, Brasil. Seu foco são crianças e jovens, e seus familiares. Suas principais atividades são oficinas (culinária, informática, corpo e mente), serviços (pedagogia, psicologia, serviço social e jornada amplia$\mathrm{da} /$ contraturno escolar) e grupos permanentes (Grupo de artesanato, Grupo de canto, Grupo de voluntários da Casa dos Girassóis, Reunião Pedagógica, Grupo de estudos). A entidade se mantém a partir de doações e venda de produtos produzidos por seu grupo de artesanato.

O grupo de artesanato teve sua primeira formação com o grupo Semeando, composto por duas coordenadoras do grupo Girassol e mulheres e jovens da comunidade, que ficou em atividade por 15 anos (VECCHIETTI, 2008). Posteriormente o grupo Semeando se dissolveu e, no início de 2010, deu-se início a um novo grupo de artesanato. Algumas das antigas integrantes do Semeando estão na nova formação. Os produtos do artesanato são vendidos principalmente nos bazares realizados nos eventos promovidos pela Casa dos Girassóis.

Os produtos artesanais são produzidos na oficina de artesanato, que ocorre no primeiro sábado de cada mês, das 14 às 18 horas, na sede da Casa dos Girassóis, e depende da disponibilidade de cada pessoa envolvida com a atividade, sendo de difícil controle. Neste sentido, suas vendas ocorrem de acordo com o que há em estoque ou a partir de uma demanda específica, como foi o caso do bazar realizado no jantar de Natal em dezembro de 2010. 


\section{Das ações, das intenções e das mãos: formação do grupo de artesanato da Casa dos Girassóis}

Em entrevista, as coordenadoras colocaram que a entidade tem interesse em ampliar e organizar a venda do artesanato para que ele alcance maiores rendimentos para a entidade. Atualmente o grupo de artesanato é formado por 15 mulheres, entre 36 e 61 anos. $O$ grupo possui duas coordenadoras e uma delas tem formação em Artes e pós-graduação em design.

No decorrer do primeiro ano de pesquisa, a partir das leituras relacionadas ao seu tema e as primeiras conversas com as coordenadoras do grupo de artesanato, pode-se perceber que era preciso conhecer a forma de organização do grupo e as motivações individuais de suas integrantes para melhor realizar o diálogo entre a teoria estudada e o grupo. Dessa forma, foi elaborado o primeiro pressuposto para este campo: a formação deste tipo de grupo está além de ações pontuais de gestão do grupo, uma vez que a motivação de suas integrantes não está, em primeira ordem, vinculada a uma questão comercial ou financeira, mas sim de convivência, elevação da auto-estima e terapia ocupacional.

Dessa forma, o tratamento pontual meramente gerencial pode não trazer os resultados esperados pela Gestão de Design, necessitando da base antropológica e sociológica para uma complementação. O segundo pressuposto foi definido a partir da informação, fornecida pelas coordenadoras do grupo de artesanato, de suas intenções em direcionar o grupo para sua profissionalização, a fim de que este venha a manter financeiramente a Casa dos Girassóis. Assim, percebeuse que existia a possibilidade das integrantes do grupo não necessariamente terem absorvido esta mudança de foco, podendo haver um conflito.

Portanto, o objetivo geral deste trabalho de campo foi conhecer as motivações pessoais das integrantes do grupo de artesanato em formação na Casa dos Girassóis em participar deste grupo com foco na produção e comercialização, buscando-se evidenciar suas intencionalidades. Para alcançá-lo, utilizouse das perguntas norteadoras, que possibilitaram elaborar os procedimentos metodológicos. Estas perguntas foram: como cada integrante se sente em relação ao seu papel no grupo? Qual a trajetória de cada integrante neste grupo? Que motivação as artesãs possuem para mudar o foco de sua atuação no grupo (saindo do terapêutico recreativo para o comercial)? Quais as expectativas em relação ao futuro do grupo?

\section{O campo: a primeira percepção, o estranhamento e a revelação}

A primeira visita ao grupo de artesanato foi anterior à proposta deste trabalho, porém, como ela promoveu uma introdução importante ao grupo, decidiu-se acrescentá-la. Ela ocorreu no dia 2 de Abril de 2011, na sede da entidade, em um sábado ensolarado. Como parte da observação participante, tomou-se parte nos momentos de abertura e fechamento dos trabalhos, 


\section{HUMANAS}

com preces e depoimentos individuais, além do lanche da tarde. A atividade de campo contou em observar o grupo e fazer registros fotográficos. Na roda de abertura dos trabalhos, foi feita apresentação pessoal desta pesquisadora e o motivo por estar ali. Abordou-se brevemente sobre a pesquisa de mestrado e sua possível contribuição para o grupo. Este momento gerou algumas dúvidas da pesquisa de campo: o quanto deveria revelar sobre a pesquisa?

De que forma estas revelações poderiam influenciar nas informações que seriam coletadas, especialmente em entrevistas? Seria ético não revelar as intenções da pesquisa? Com Foote-Whyte (1980) pode-se perceber que o detalhamento da pesquisa nem sempre é necessário e vai depender do quanto o interlocutor deseja saber. No grupo da Casa dos Girassóis, não foram exigidos mais detalhes sobre a pesquisa, contudo, não é possível saber até que ponto esses detalhes não foram apresentados pela colaboradora (informante) da pesquisa. Novamente Foote-Whyte (1980) contribui no entendimento de um aspecto importante do trabalho de campo: o que acontece quando o pesquisador não está por perto dificilmente será de conhecimento do pesquisador e, assim como ele observa, é observado.

Quando afastado do grupo observado o pesquisador não tem acesso ao que pensam realmente a seu respeito, tampouco dos acordos internos feitos pelos pesquisados. Pode-se perder informações interessantes para a pesquisa, caso não haja um informante confiável para relatar o que ocorre nos bastidores. No caso de Foote-Whyte, por se tratar de um campo fechado, o risco à sua integridade física e até mesmo à vida era iminente. No caso desta pesquisa, arriscou-se perder informações ou ter os depoimentos direcionados por interesses internos ao grupo.

Ainda nesta primeira visita percebeu-se que havia uma possível divisão social no grupo. Parte das integrantes do grupo de artesanato podem ser categorizadas como pertencentes às camadas médias, enquanto a outra parte como pertencentes às camadas populares. É importante colocar que esta classificação, neste trabalho, ocorreu num primeiro momento de forma intuitiva, a partir da observação do local e das pessoas.

Utilizou-se Heilborn (2004) para apresentar o problema de definição das camadas médias. Na literatura, camadas médias são definidas, principalmente, por aquilo que não são; ou que estão entre a aristocracia e o proletariado, ou seja, a burguesia. Burguesia tanto, por um lado, restringe como, por outro, abrange demasiadamente, não definindo a contento o que seriam as camadas médias (HEILBORN, 2004; p. 71). A autora apresenta o argumento de Gay (1989) que diz que a dificuldade em se definir as classes médias é constitutivo das mesmas. Por sua vez, falando-se da definição de camadas populares, reportase a levantamento teórico anterior, em pesquisa realizada durante curso de especialização que realizado no ano de 2009. 


\section{Das ações, das intenções e das mãos: formação do grupo de artesanato da Casa dos Girassóis}

Nesta pesquisa, baseando-se nos autores Antonio Augusto Arantes (2006), Nelson de Araújo (1988; 1986), Clodovis Boff (1986), Lina Bo Bardi (1994), Vivian Catenacci (2009) e Melo Neto (2002), pode-se chegar a um levantamento histórico que demonstra que "cultura popular" remete a um amplo espectro que vai desde a negação (implícita ou explícita) de que suas manifestações contenham alguma forma de conhecimento (visão elitista de camadas populares) até a atribuição do papel de resistência contra a dominação de classe por parte das camadas populares, observando-se uma tendência na manutenção do entendimento de povo e de popular dentro das relações de poder das sociedades estratificadas e divididas entre setores detentores do poder e dos modos de produção e setores reféns desta estrutura de poder. Apesar do levantamento feito, percebe-se que, assim como camadas médias, camadas populares é de difícil conceituação.

Nesta primeira visita, houve o primeiro estranhamento com o campo em virtude do trabalho filantrópico de caráter assistencialista desenvolvido pela Casa dos Girassóis, que segue um padrão recorrente no Brasil de obras de caridade da classe média para as camadas populares. No momento de reunião para discutir os novos rumos do artesanato na Casa dos Girassóis, proposta das coordenadoras, visualizou-se uma separação espacial espontânea: mulheres brancas de camadas médias de um lado e mulheres negras de camadas populares de outro.

Esta visualização levou à ideia de que as motivações para estarem no grupo de artesanato eram diferentes. Inferiu-se, neste primeiro momento que, as mulheres das camadas populares eram assistidas pela Casa dos Girassóis, buscando amenizar os possíveis problemas sociais que vivenciavam na comunidade, muito provavelmente, filhos aliciados (ou em vias de) pelo crime organizado, maridos violentos ou ausentes, baixa autoestima, geração de renda extra pelo artesanato etc. Por sua vez, as mulheres das camadas médias, seriam trabalhadoras voluntárias da Casa dos Girassóis, praticantes do espiritismo, com famílias sólidas e mantidas, principalmente, por maridos bem posicionados socialmente, e que utilizavam o tempo livre para praticar a caridade ajudando as mulheres daquela comunidade. Esta visão se mostrou um bom exemplo do que Wacquant (1996) coloca como tendência estigmatizadora do gueto. O autor faz uma colocação importante: ao analisar o gueto, ou outras comunidades distantes da realidade do pesquisador e historicamente estereotipadas, é comum que os relatos evidenciem o que estes grupos possuem de mais diferente, em relação à cultura do pesquisador.

No caso dos guetos, "os moradores mais pobres, ameaçadores e malafamados do núcleo urbano racialmente estigmatizado são caracteristicamente vistos como representantes de todo o gueto" (WACQUANT, 1996; pp. 151-52). 


\section{HUMANAS}

Para fugir dessa tendência, o pesquisador deve evitar o julgamento sobre uma suposta imoralidade e focar na vida cotidiana, em suas banalidades corriqueiras, as formas de conduta etc (WACQUANT, 1996; p. 153). É tratar o gueto, ou qualquer outra comunidade distante, "com os mesmos princípios analíticos e conceitos usados para entender qualquer outro sistema social" (WACQUANT, 1996; p. 153). Foi justamente a partir do momento que a pesquisa de campo permitiu conhecer o grupo e suas integrantes individualmente que alcançou-se um entendimento de sua constituição.

Neste sentido, as entrevistas individuais semi-estruturadas e as conversas informais permitiram conhecer cada integrante individualmente em suas próprias palavras. Por sua vez, as observações possibilitaram conhecer a interação dessas mulheres, o que foi imprescindível para eliminar o entendimento preliminar de divisão de classes dentro do grupo. Mesmo que esta divisão exista, ela não se configura da maneira como foi imaginada. E as relações interpessoais mostraram-se mais fortes do que uma divisão social. Principalmente devido ao fato de que a maioria dessas mulheres se conhecia há pelo menos dez anos. Os trabalhos do grupo espírita e, mais recentemente, da Casa dos Girassóis, configuram-se como ponto de encontro dessas convivências.

No campo pode-se perceber que o foco de atuação de todas ali é garantir às crianças da comunidade atividades que as retire do convívio com a rua nos tempos livres. Este objetivo comum as aproximou de tal forma que elas se acompanham inclusive nos momentos mais íntimos como gravidez e nascimento dos filhos e netos, casamentos, enfermidades e conquistas (como a casa que uma delas comprou recentemente). Estas revelações surgiram nas respostas às questões apresentadas a seguir. Estas entrevistas foram realizadas individualmente em local afastado das demais integrantes, contudo, tem-se entendimento que, este afastamento não garante a ausência de troca de informações entre as entrevistadas enquanto a pesquisadora não estava por perto:

1. Por que entrou para o artesanato? Teve as seguintes respostas: gosta muito; terapia; relaxamento; aprender a bordar; foi convidada; porque gosta; para conhecer; afinidade (formação em Artes); convite de uma das coordenadoras; lazer preferido;

2. Que diferença o artesanato fez na sua vida? Teve como respostas: satisfação; retorno financeiro para a Casa e amizades (grupo acolhedor); está mais calma; trouxe coisas boas, aprendizados; acalma. Terapia; terapia; descobrir que gosta de artesanato; forma de expressão, sentir-se bem, contato com a essência; realização e relaxamento; lazer preferido; 3. Na sua opinião, qual objetivo do artesanato na Casa dos Girassóis? As respostas foram: não deve faltar. Ponto de encontro das amigas. Ajuda mútua. A comunidade é uma família. O artesanato é muito válido; retorno 


\section{Das ações, das intenções e das mãos: formação do grupo de artesanato da Casa dos Girassóis}

financeiro para a Casa (para as crianças); trocar ideias. Relacionamento. Caiu como uma luva; São tantos benefícios. Ocupação para as crianças; Auxiliar para manter a casa (fonte de renda); Ajuda para a Casa e um conhecimento pra gente; Aprender e ensinar e ajudar com a renda da Casa; Primeiro, manter (auxílio) a Casa. Terapia, oportunidade de trabalhar com a autoestima; geração de renda. Um meio; Renda extra (complemento); Para o público carente, autoestima, valorização pessoal, criatividade, possuir renda. Trabalho do grupo, união das pessoas. Energia boa, novos valores de vida pela vivência;

4. Três palavras que definem a Casa dos Girassóis para você: amor, confiança, educação; amor, caridade, família; socorro, coração de mãe, amizade; nota mil, tudo de bom, renascer; amor, compreensão, esperança; conhecimento, segurança, companheirismo; aconchego, carinho, família; trabalho, amor, esperança; amor, prazer, dedicação; alegria, crescimento espiritual, necessidade;

5. Três palavras que definem você na Casa dos Girassóis: disciplina, limpeza, confiança; amor, caridosa, amiga; eu sou dez, amiga, companheira; querida, a mãe de todos, uma estrela; amizade, participação, entendimento; conhecimento, coleguismo, ajuda; sensível, dedicada, feliz; responsabilidade, envolvimento, aprendizado; satisfeita, realizada, esperançosa; necessária, responsável, amor.

Estas respostas ajudam a perceber que, independente da situação social, todas veem aquele trabalho e o estar ali como algo importante para a comunidade. Da mesma forma, todas possuem uma motivação de ordem pessoal para estar ali, além da ajuda às crianças da comunidade. Seja para encontrar as amigas, seja para ter um momento de terapia, seja por relaxamento, seja para aquisição e transmissão de conhecimento, seja por gosto pela atividade, estas motivações não possuem um traço social, mas pessoal e, portanto, individual.

Além das entrevistas e das observações, outro recurso contribuiu para conhecer melhor o grupo e suas individualidades: a elaboração de um mapa mental em grupo. No dia 18 de junho realizou-se com o grupo duas atividades focadas na pesquisa de mestrado: a elaboração de um mapa mental visando sintetizar os objetivos do artesanato da Casa dos Girassóis e as características desse artesanato para o grupo e a construção de um painel semântico para levantamento de imagens que sintetizem a identidade do grupo. Estas ferramentas são utilizadas nos procedimentos metodológicos do design participativo, que visa a resolução de um problema prático de forma coletiva (VEZZOLI, 2010). Neste trabalho, estas atividades fazem parte do levantamento de oportunidades para a Casa dos Girassóis: participação no Balcão da Cidadania; 


\section{HUMANAS}

definição da identidade do artesanato da casa (o que facilitou o desenvolvimento de sua identidade visual) e levantamento de novas oportunidades por meio do artesanato.

Os mapas mentais são um tipo de diagrama que auxiliam na organização de informações, de conceitos e ideias, favorecendo o processo de aprendizado e a visualização de um problema ou situação. Do inglês, mind map, foi criado em 1970 por Tony Buzan. Compreende uma técnica gráfica para expressar o pensamento radial, ou seja, que conecta ideias a um ponto central formando uma rede. Sua construção segue as seguintes etapas: 1) colocação do tema principal (imagem ou palavra-chave) no centro da página; 2) são feitas ramificações com os subtemas relativos ao tema central; 3) cada subtema pode ter ramificações com palavras ou imagens associadas; 4) as ramificações formam uma estrutura nodal conectada (MENTO et al., 1999; p. 392-93). Eles podem ser aplicados a qualquer tipo de tarefa, individual ou em grupo, para planejar e registrar graficamente qualquer tipo de evento.

Para a atividade na Casa dos Girassóis, o mapa mental buscou auxiliar organização de pensamentos, ideias e conceitos que o grupo de artesan gerar sobre sua condição de grupo atual e futura (organização do grupo) e s ideias e desejos em relação à produção artesanal do grupo. Este tipo de pro dimento faz parte da metodologia de design participativo (VEZZOLIi, 201 Portanto, o foco do mapa mental foi ARTESANATO DA CASA DOS । RASSÓIS. Com seu resultado (Figuras 1 e 2) foi possível observar como c: uma das integrantes estava em relação ao novo desafio do grupo: produzir $\mathrm{p}$ gerar renda para a entidade de forma mais profissional.

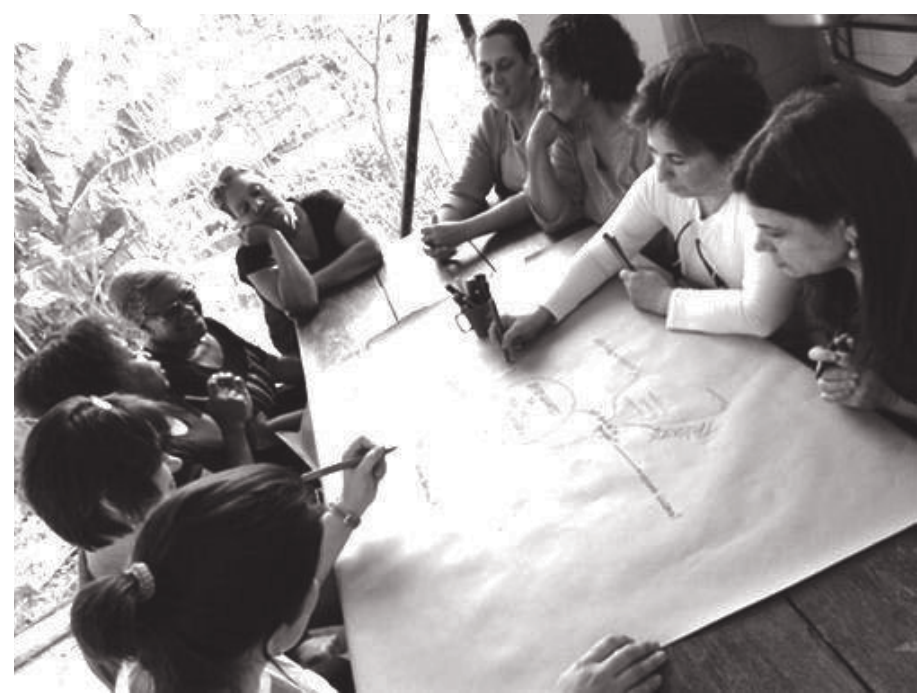

Figura 1

Início da elaboração do mapa mental em grupo. 


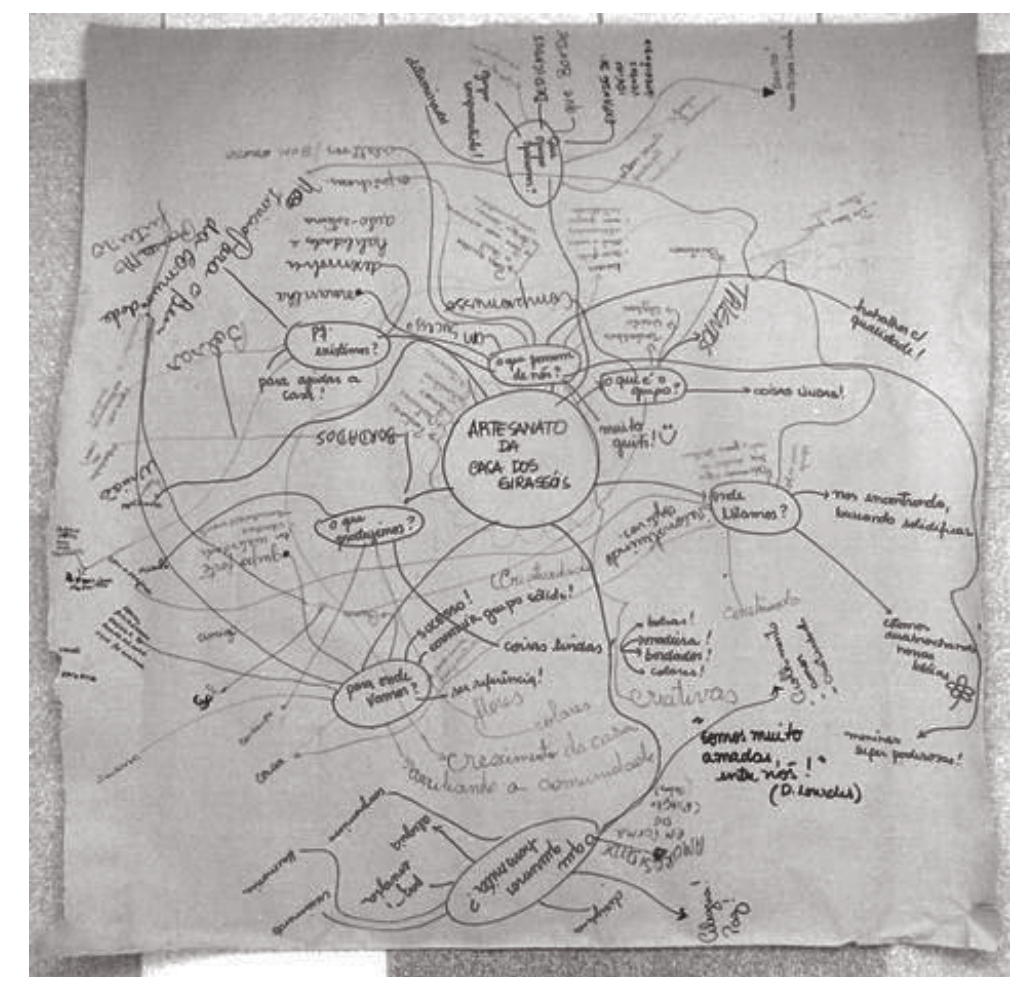

Figura 2

Mapa mental finalizado.

Já os painéis semânticos são painéis de imagens, desenhos, texturas ou outras manifestações gráficas que sintetizam conceitos relacionados a um tema central. Muito utilizados em marketing e em design, auxiliam na síntese visual para desenvolvimento de produtos (gráficos, artefatos, ambientes etc.). Podem ser divididos por temas, tais como, cores e sensações, formas e expressividade, produtos similares etc. Podem ser construídos com recorte e colagem ou diretamente no computador com auxílio de ferramentas gráficas. Este tipo de painel recebe uma variedade de nomes, mas seu objetivo é o mesmo (PEDROSO \& LAMÓGLIA, 2005).

A atividade de construção dos painéis semânticos foi a que revelou conflitos de ordem subjetiva, por se tratar de uma atividade criativa, que exigiu seleção de imagens, análise e organização das mesmas no espaço do papel de forma coletiva. Nesta atividade, após a explicação de como ela seria e da disponibilização dos materiais, as integrantes do grupo se organizaram espontaneamente em dois grupos. Os materiais disponíveis eram: papel pardo, revistas, tecidos, botões, novelos de lã, tesouras, cola e fita adesiva. 


\section{HUMANAS}

Um dos grupos decidiu fazer uma boneca com retalhos e fios (Figura 3). O outro, focou no painel com fotos e pequenas montagens de materiais específicos do artesanato (Figura 4). Nesta atividade ficou evidente a visão individual de cada uma com relação às imagens e materiais que se relacionam ao trabalho do grupo. Aquelas que focaram no painel da boneca tiveram muitos conflitos na escolha de tecidos, fitas e acessórios para compô-la. Este painel causou um certo desconforto nas coordenadoras. Esta atividade evidenciou que o grupo, mesmo guardando objetivos pessoais comuns, possui dificuldades na criação em conjunto. Permanece em sua organização interna a divisão entre o trabalho intelectual e o trabalho manual, e, enquanto poucas exercem o primeiro, a maior parte das integrantes se concentra no segundo.

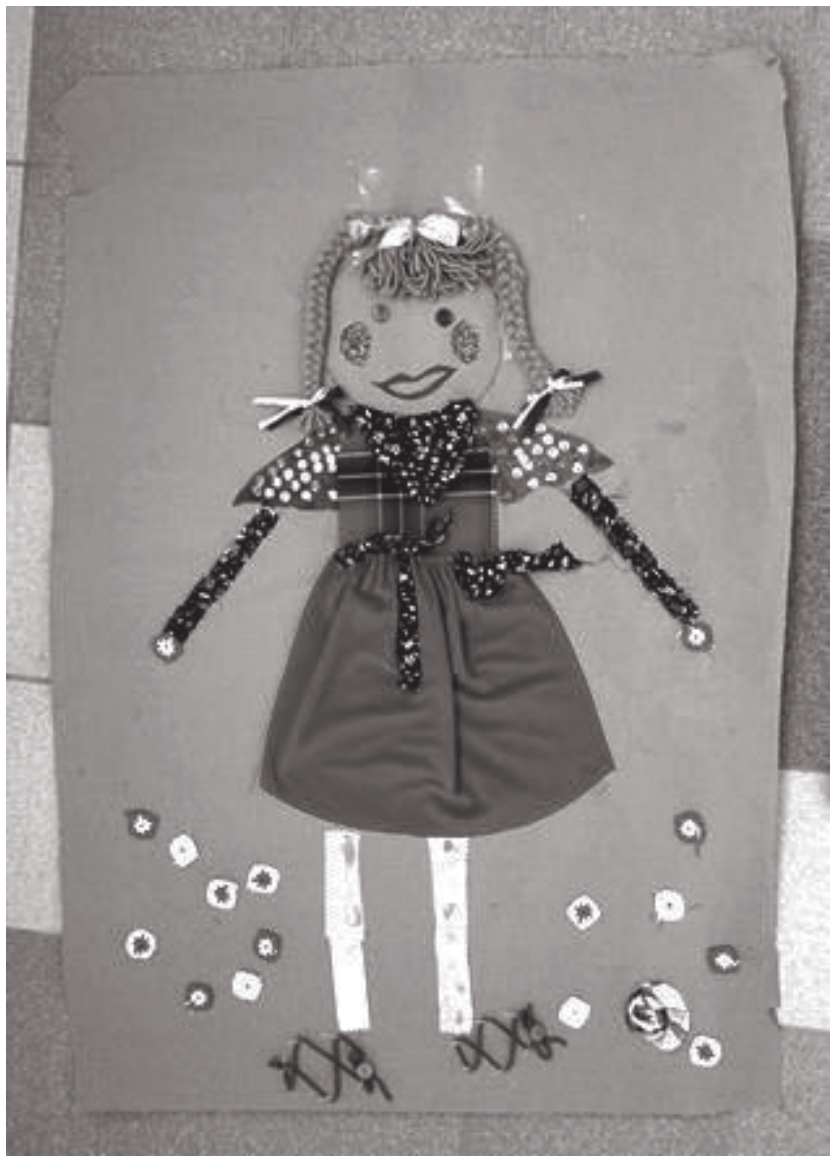

Figura 3

Painel Semântico do grupo da boneca. Fonte: a autora, 2011. 


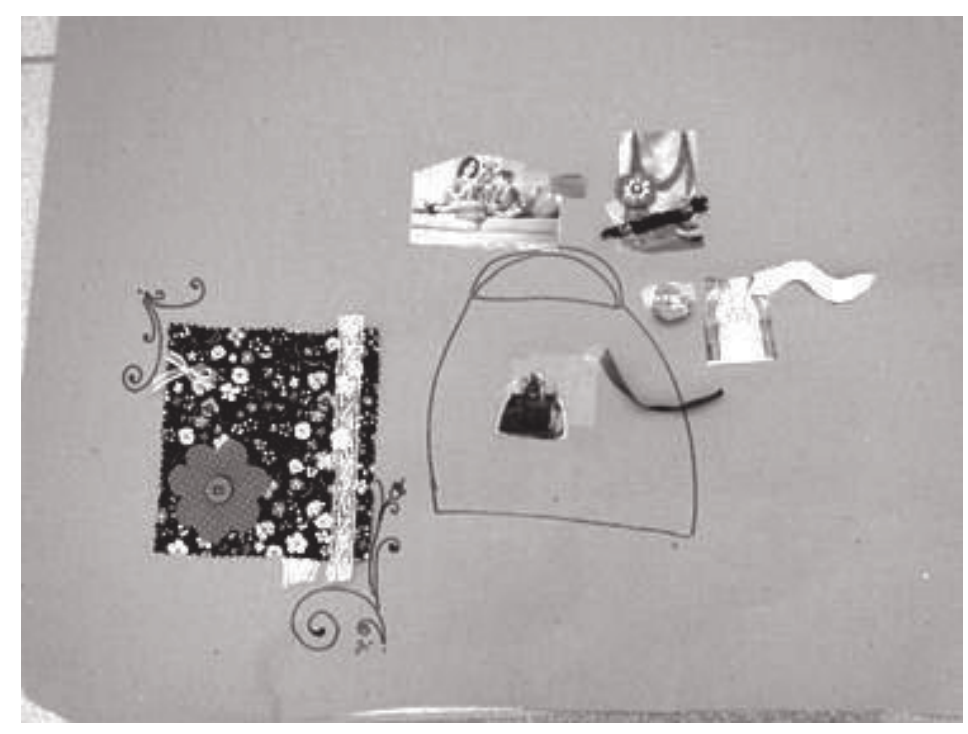

Figura 4

Painel Semântico do grupo das pequenas montagens. Fonte: a autora, 2011.

Ao final da atividade, aproveitou-se para fazer um fechamento perguntando o que elas tinham achado das atividades e quais suas dificuldades. Todas colocaram ser positivo e válido. Demonstraram ter gostado mais do mapa mental, pois ele permitiu sintetizar os pensamentos delas em relação ao artesanato. Acredita-se que esta preferência também seja pelo fato dele ter mantido a construção em grupo sem conflitos, o que não ocorreu no painel semântico. Da mesma forma, trabalhar com palavras é mais fácil que trabalhar com imagens, pois as imagens precisam ser selecionadas e interpretadas para serem reelaboradas e o nível de abstração necessário para isso é maior do que na seleção de palavras-chave.

\section{Considerações finais}

Esta breve experiência com a Antropologia possibilitou avanços importantes para a pesquisa de campo no mestrado em Gestão de Design. A introdução aos autores e temas de base desta disciplina, bem como o exercício etnográfico, mesmo que breve, permitiram adentrar em questões que não estavam previstas na pesquisa, mas que interferiam em seu andamento.

O ponto principal foi conhecer o grupo e as motivações individuais de suas integrantes em participar dele, bem como em continuar no grupo mesmo com sua mudança de foco: saindo do terapêutico e recreativo para alcançar uma profissionalização. Dessa forma, os autores que tratam do trabalho de campo foram de grande ajuda na montagem dessa experiência etnográfica. 


\section{HUMANAS}

Também foi possível resolver conflitos pessoais em relação ao grupo do estudo de caso e complementar questões observadas na base teórica da pesquisa.

Partindo-se para os resultados deste campo, concluiu-se que, de modo geral, as integrantes do grupo de artesanato se sentem realizadas em participar do grupo, contudo gostariam de se dedicar mais e melhor, seja em relação a mais tempo de dedicação, seja em relação a melhorar sua qualidade de produção. Com relação às suas trajetórias individuais no grupo, boa parte já realizava algum tipo de trabalho artesanal, aprendido de forma autônoma, e este fato foi motivador para participar do grupo de artesanato da Casa dos Girassóis.

Revelou-se também que as principais motivações para participar do grupo são pessoais, que vão desde terapia e momento para si, a encontro com as amigas e possibilitar uma ajuda à entidade e, consequentemente, às crianças da comunidade do MontSerrat. Por sua vez, esta última é a principal motivação para mudar o foco de sua atuação no grupo saindo do terapêutico e recreativo para o comercial: ajudar financeiramente a entidade para a manutenção de seus trabalhos. Finalmente, com relação às expectativas em relação ao futuro do grupo, todas são otimistas e confiantes. No mapa mental, foram colocadas as expressões: "sucesso"; "construir um grupo sólido"; "ser referência"; "auxiliando a comunidade"; "grupo forte em: criatividade, vendas e amadurecimento"; "vamos futuramente ensinar, passar adiante o que foi ensinado".

O trabalho antropológico se realiza no campo. Da mesma forma é o design, que se concretiza no campo, saindo da mente do designer e entrando na vida das pessoas. Este aspecto possibilitou aproximar as duas áreas e entender como a antropologia poderia complementar o design.

\section{Referências bibliográficas}

ARANTES, A.A. O que é cultura popular. $14^{\mathrm{a}}$ Edição. São Paulo: Brasiliense, 2006.

ARAÚJO, N. de. Folclore e política. Salvador: Universidade Federal da Bahia/Ianamá, 1988.

ARAÚJO, N. de. Pequenos mundos: um panorama da cultura popular da Bahia. Tomo 1 - O Recôncavo. Salvador: UFBA, 1986.

BOFF, C. Como trabalhar com o povo: metodologia do trabalho popular. $7^{\text {a }}$ Edição. Petrópolis: Vozes, 1986.

BO BARDI, L. Tempos de grossura: o design no impasse. São Paulo: Instituto Lina Bo Bardi e P.M. Bardi, 1994 
CATENACCI, V. Cultura popular: entre a tradição e transformação. São Paulo Perspec., 15(2): 28-35, 2001.

FOOTE-WHYTE, W. Treinando a observação participante. In: Desvendando máscaras sociais. p. 77-86. Rio de Janeiro: Francisco Alves, 1980.

HEILBORN, M.L. Dois é par - gênero e identidade sexual em contexto igualitário. Rio de Janeiro: Editora Garamond, 2004.

MELO NETO, J.F. O que é popular? Disponível em: http://www.prac.ufpb.br/ copac/extelar/producao_academica/artigos/pa_a_2002_o_que_e_popular.pdf. Acesso: 27 de Outubro/2009.

MENTO, A.J.; MARTINELLI, P. \& JONES, R.M. Mind mapping in executive education: applications and outcomes. Journal of Management Development, 18(4): 390-407, 1999.

MICHAELIS Moderno Dicionário da Língua Portuguesa. Disponível em $<$ http:/ /michaelis.uol.com.br. Acesso: 12 de Julho/2011.

ORTNER, S. Poder e Projetos: reflexões sobre a agência. In: M. GROSSI, C. ECKERT \& P. FRY (Orgs.). Conferências e diálogos: saberes e práticas antropológicas. p. 45-80. Brasília e Blumenau: ABA e Nova Letra, 2007.

PEDROSO, D.M.W. \& LAMÓGLIA, F.B. Painel semântico como metodologia para construção de marca. Gestão: Revista Científica de Administração, 5(5): jul/dez, 2005.

VECCHIETTI, M.C. Pesquisa etnográfica Grupo Semeando. Florianópolis: UDESC, 2008 (originalmente apresentado como trabalho final da disciplina Antropologia da Educação, Curso de Pedagogia, UDESC).

VEZZOLI, C. Design de sistemas para a sustentabilidade: teoria, métodos e ferramentas para o design sustentável de "sistemas de satisfação". Salvador: EdUFBA, 2010.

WACQUANT, L. Três premissas perniciosas no estudo do gueto norte-americano. Mana, 2(2), Rio de Janeiro, 1996. 